\title{
Relationships Between Internet Use and Sleep Duration in Chinese Adults: A Cross-Sectional Study
}

\author{
Zhao-Ya Fan \\ Ruo-Yun Yin \\ Lei Tang \\ Chang-Hong Zhang (D) \\ Fan Zhang
}

School of Public Health and Management, Research Center for Medicine and Social Development, Collaborative Innovation Center of Social Risks Governance in Health, Chongqing Medical University, Chongqing, 400016, People's Republic of China
Correspondence: Fan Zhang

School of Public Health and Management, Research Center for Medicine and Social Development, Collaborative Innovation Center of Social Risks Governance in Health, Chongqing Medical University, Chongqing, 400016, People's Republic of China

Tel $+86+13983782377$

Fax +862368485068

Email epicqmu@।63.com
Purpose: Most studies that examined the relationship between internet use and sleep were conducted mainly in children and adolescents, and we know little about the use of internet among adults. The purpose of this study is to understand the internet use patterns of Chinese adults and to measure their associations with sleep duration from variety, frequency and type. Methods: A total of 19,730 samples were selected from 2018 data of the China Health and Retirement Longitudinal study. Internet usage was obtained by specific questions, and the range of sleep period was grouped according to recommendations from the National Sleep Foundation. Kruskal-Wallis $H$-test and the chi-squared test were used for basic descriptive analysis, and multinomial logistic regression was used to analyze the relationships between internet use and sleep duration. Stata version 15.0 was used for data cleaning, and SPSS version 20.0 was used for statistics analysis.

Results: After screening, a total of 6346 persons were included in the analysis, of which 3148 (49.61\%) were males and 3198 (50.39\%) were females. Age ranged from 21 to 95 years, most persons were over 45 years old, with the median age of 56 years. Only $1180(18.59 \%)$ participants used the internet, and almost all of them used mobile phones $(1137,96.36 \%)$, the other three types were desktop computer $(232,19.66 \%)$, laptop computer $(69,5.85 \%)$ and tablet (73, 6.19\%). There were 912 (77.28\%) and 268 (22.71\%) participants who used only one and two or more types, respectively. In the unadjusted model, both short sleep and long sleep were associated with internet use compared with normal sleep duration $(0.806$ [0.708-0.918] $\mathrm{p}=$ $0.001 ; 0.345[0.251-0.475] \mathrm{p}<0.000)$. After adjusting for all covariates, the association between long sleep and internet use still persisted $(0.612[0.433-0.865] \mathrm{p}=0.005)$, but no significant difference was found in short sleep $(0.929[0.803-1.075] \mathrm{p}=0.325)$

Conclusion: Internet use was found to be closely associated with sleep and the duration of sleep negatively affected, which may provide new ideas for sleep hygiene recommendations and healthy media use. This conclusion needs more evidence to support.

Keywords: China, cross-sectional study, sleep duration, internet use

\section{Introduction}

Along with the development of digitization, society is also evolving, and many activities and services occur on the internet. If persons do not use the internet or do not pay attention to the development of internet services, it will be difficult to participate in activities that no longer occur in reality. This has also resulted in a digital divide among groups, with the older generation particularly affected. ${ }^{1}$ According to the 45th Statistical Report on Internet Development in China, there were approximately 904 million internet users in China by the end of March 2020, 
and the internet penetration rate reached $64.5 \%$, of which internet users aged 50 and above accounted for $16.9 \%{ }^{2}$ Unlike conventional electronic devices such as televisions and game consoles, new portable mobile devices with broader functions such as the internet and social networking, allow real-time interaction, which further extends the duration of user use and increases the possibility of addiction. Sleep duration is an important factor health-related factor that plays a role in the development of many diseases. ${ }^{3}$ Lack of sleep can lead to decreased in glucose tolerance and insulin sensitivity. ${ }^{4}$ A meta-analysis showed that persons who had difficulty falling asleep had a $57 \%$ increased risk of developing diabetes compared to those who slept normally. ${ }^{5}$ Sleep disorders also affect lipid metabolism. ${ }^{6}$ A cross-sectional study in Japan showed that sleep quality was associated with non-alcoholic fatty liver disease, and there were gender differences. ${ }^{7}$ Sleep disorders, such as sleep loss, sleep deprivation, and insomnia, have been recognized as common problems in modern society. ${ }^{8}$

The COVID-19 pandemic has increased search queries for insomnia on Google in the worldwide, with the number in the United States is increasing by $58 \%$ during the first five months of 2020 compared to the same months of the previous three years. ${ }^{9}$ The findings showed that computer users were often at risk for less than 5 hours of sleep compared to the $7-8$ hour average. ${ }^{10}$ A previous study showed that bedtime mobile phone use also had an effect on sleep patterns in adults. Among younger respondents, the increase in bedtime mobile phone use was associated with more fatigue and later rise times; but among older respondents, it was associated with shorter sleep duration and earlier rise time. ${ }^{11}$ During social isolation of the COVID-19 pandemic, many parts of the world restricted citizens from going outside or staying outdoors for long periods of time. ${ }^{12}$ As an information dissemination medium, the internet is an important way to disseminate health information and is also closely related to personal health. ${ }^{13}$ In disease management, people can use the internet to seek information about health conditions, such as symptoms and treatment. Studies have shown that adults will search for health information online whether they have chronic diseases or not, while patients seem to be more active in electronic health behaviors in searching for health information, tracking health indicators and using patient portals. ${ }^{14}$ At the same time, the emergence of telemedicine platforms has expanded the operation model of medical services and alleviated the problem of unbalanced distribution of offline medical resources, During the COVID-19 pandemic, doctors' remote consultations through the internet effectively avoiding unnecessary contact, providing safer health care services and meeting the public's need for convenient access to medical help. ${ }^{15}$

While the internet penetration rate continues to increase and people's growing demand for health, exploring whether and how internet use affects adults' sleep is an important direction worthy of research in the field of health. Therefore, our study aimed to understand the internet use patterns of Chinese with data from an ongoing nationally representative longitudinal study and to investigate the relationship between internet use and sleep duration from three dimensions: variety, frequency and type.

\section{Materials and Methods}

\section{Participants}

Our data were collected from the latest China Health and Retirement Longitudinal Study (CHARLS) Wave 4. CHARLS is a nationally representative study involving a longitudinal survey of residents aged 45 and over and their partners, started in 2011, followed up with participants every 2 years, and covered 450 villages in 150 counties of 28 provinces in China. Informed consent was obtained from all participants. The biomedical ethics committee of Beijing University approved the study, and detailed descriptions of the survey design and procedures were reported in the original study documentation. ${ }^{16}$

Wave 4 collected a total of 19,752 participants, and the finally 6346 of them were included in our study. Specific reasons for exclusion and the selection procedure are shown in Figure 1.

\section{Measures}

\section{Internet Use}

In the Wave 4 questionnaire, internet use was measured using the following three questions: (1) Have you used the Internet in the last month; (2) Which types of devices do you use to access the Internet: Desktop computer/ Laptop computer/ Tablet computer (such as IPAD)/ Cellphone/ Other devices; (3) How often have you used the Internet in the last month.

Variety: according to the answer to the second question, in order to avoid too few participants of each type, the variable was divided into three groups: None/ 1 type and $\geq 2$ types. 


\section{A total of 19752 respondents in Wave 4}

\section{Merging variables from CHARLS raw data Exclude:}

22 respondents with missing Internet use; 12650 respondents with missing prevalence of chronic diseases;

173 respondents with missing age;

12 respondents with missing personal income;

\section{9 respondents with missing health status.}

\section{6 respondents were included in this study}

Figure I Flow chart of sample selection.

Frequency: answers to the third question were: almost daily/ almost every week and not regularly. In order to avoid too few participants of each type, we re-categorized this variable into three groups: never/ not regularly and regularly (including almost daily and almost every week).

\section{Sleep Duration}

In the Wave 4 questionnaire, the range of sleep duration was measured using specific item: During the past month, how many hours of actual sleep did you get at night (average hours for one night)? (This may be shorter than the number of hours you spend in bed). According to the National Sleep Foundation, ${ }^{17}$ sleep time was divided into three groups: short sleep duration group $(\leq 6 \mathrm{~h})$; normal sleep duration group (6-9 h); and long sleep duration group ( $\geq 9 \mathrm{~h}$ ). This criterion has also been used in other studies of Chinese population. ${ }^{18}$

\section{Other Covariates}

Age, gender, marital status, education, and annual personal income were included in the demographic and socioeconomic variables. In terms of marital status, the unmarried group included persons who had never been married, separated, divorced, or widowed. Education was divided into five levels: (1) illiteracy; (2) elementary school; (3) middle school; (4) high school and (5) college and above. "Illiteracy" also included those who did not complete primary school education, and old-style private school was considered to be at the same level as elementary schools.

Smoking, drinking, and exercise were included in the health behavior variables. Participants who reported quitting smoking were included in the non-smoker group.

Self-reported health status and the number of chronic diseases were included in the health status variables. There 
were five options for health status in the questionnaire: (1) very poor; (2) poor; (3) fair; (4) good; and (5) very good. Respondents who answered "very good" or "good" were assigned to the "good" group and participants who answered "very poor" or "poor" were assigned to the "poor" group. A total of 14 common chronic diseases were included in the CHARLS questionnaire, and the prevalence was evaluated by self-report. The 14 chronic diseases were listed below: (1) hypertension; (2) dyslipidemia; (3) diabetes or high blood sugar; (4) cancer or malignant tumor; (5) chronic lung diseases; (6) liver disease; (7) heart attack (including coronary heart disease, angina, congestive heart failure, or other heart problems); (8) stroke; (9) kidney disease; (10) stomach or other digestive diseases; (11) emotional, nervous, or psychiatric problems; (12) memory-related disease; (13) arthritis or rheumatism and (14) asthma.

\section{Statistical Analysis}

Participants were divided into three groups based on sleep duration and described basic characteristics. Categorical variables were displayed as percentages. For continuous variables, mean and standard deviation were used if data matched normal distribution, otherwise the median and interquartile range were used. Differences in age was calculated using the non-parametric Kruskal-Wallis $H$-test, and differences in other characteristics were calculated using the Chi-squared test. The association between internet use and sleep duration was assessed using multinomial logistic regression model. Multinomial logistic regression was an extension of logistic regression, which was suitable in cases where the nominal result had more than two disordered categories/levels. Odds ratio (OR) and 95\% confidence interval $(\mathrm{CI})$ were used to describe the association between results and explanatory variables, and other covariates were controlled. We adjusted age and gender in model 1, and further adjusted marital status, education, annual personal income, health behaviorrelated factors; and health status in model 2. Whether to use the internet, frequency and variety of use, whether to use desktop/cellphone/laptop/tablet were used as outcomes. We also performed post hoc power analysis using G-power 3.1.9.7 (Kiel University, Kiel, Germany) software to test the power of our study. The power $(1-\beta)$ was determined to be 0.999 , based on an error probability of 0.05 , and a total sample size of 6346 . The significance level was set to 0.05 (two-tailed). The data was cleaned using Stata version 15.0 (Stata Corporation LP, College
Station, TX, USA) and analyzed using SPSS version 20.0 (SPSS, Inc., Chicago, IL, USA).

\section{Results}

\section{Characteristics of Study Population}

The characteristics of the whole sample were listed in Table 1. A total of 6346 samples were included, including 3148 (49.61\%) males and 3198 (50.39\%) females. Most of the samples were middle-aged and elderly people, with the oldest as 95 years old and the youngest as 21 years old. The number of people aged under 45 years old, 45 to 59 years old, 60 to 69 years old, 70 to 79 years old and over 80 years old were 145, 3627, 1732, 635 and 207 respectively. The majority of respondents were married $(80.62 \%)$, with an educational level of middle school or lower (85.06\%), had an annual income $\leq 5 \mathrm{k}$ RMB (58.34\%), exercised regularly $(92.74 \%)$, did not consume alcohol (61.44\%) or smoke (67.18\%), did not suffer from chronic diseases $(58.78 \%)$, and self-reported health status was fair $(48.05 \%)$ or good $(39.14 \%)$.

In terms of internet usage, there were 1180 (18.59\%) persons who used the internet in the last month, of which, 1077 (91.27\%) persons used it regularly (991 persons almost daily and 86 persons almost every week), 912 (77.28\%) persons used only one type of device, and 268 (22.71\%) persons used two or more devices. Among the four devices, cellphone was the most popular (96.36\%).

\section{Association Between Internet Use and Sleep Duration}

Table 2 presents the relationships between sleep duration the three dimensions of internet use, including variety, frequency and type. Among the participants, the short sleep group, normal sleep group and long sleep group were 3041 (47.92\%), 2778 (43.78\%) and 527 (8.30\%), respectively. In the unadjusted model, internet use was significantly associated with both short and long sleep $(0.806$ [0.708-0.918] $p=0.001 ; 0.345[0.251-0.475] p<$ 0.001). Compared with the long sleep group, persons who frequently used the internet were more likely to have short sleep ( 0.811 VS 0.328 ), and the probability of using more than two types of devices was also higher in the short sleep group (0.691 VS 0.154).

Age, gender, marital status, economic level, education, smoking, drinking, exercise, subjective health, and number of chronic diseases were significantly different according to the sleep duration. Among the persons who use the internet, 
Table I The Characteristics of Study Variables

\begin{tabular}{|c|c|c|c|c|c|c|}
\hline Variables & $\begin{array}{l}\text { Total } \\
(n=6346)\end{array}$ & $\begin{array}{l}\text { Short Sleep } \\
(n=3041)\end{array}$ & $\begin{array}{l}\text { Normal Sleep } \\
(n=2778)\end{array}$ & $\begin{array}{l}\text { Long Sleep } \\
(n=527)\end{array}$ & $\chi^{2}$ & $p$ \\
\hline Gender & & & & & $6.938^{\mathrm{a}}$ & 0.031 \\
\hline Male & $3148(49.61 \%)$ & | 466 (48.2I\%) & $1430(5 \mathrm{I} .48 \%)$ & 252 (47.82\%) & & \\
\hline Female & $3198(50.39 \%)$ & 1575 (51.79\%) & 1348 (48.52\%) & $275(52.18 \%)$ & & \\
\hline Age (years) & $56(50,65)$ & $56(51,65)$ & $55(50,64)$ & $60(51,69)$ & $64.755^{\mathrm{b}}$ & $<0.001$ \\
\hline Marital status & & & & & $25.181^{\mathrm{a}}$ & $<0.001$ \\
\hline Married & $5116(80.62 \%)$ & 2410 (79.25\%) & $2310(83.15 \%)$ & 396 (75.14\%) & & \\
\hline Unmarried & $1230(19.38 \%)$ & 631 (20.75\%) & $468(16.85 \%)$ & I3| (24.86\%) & & \\
\hline Education & & & & & $102.540^{\mathrm{a}}$ & $<0.001$ \\
\hline Illiteracy & 2309 (36.39\%) & II 52 (37.88\%) & 883 (31.79\%) & 274 (51.99\%) & & \\
\hline Elementary school & 1465 (23.09\%) & $686(22.56 \%)$ & $664(23.90 \%)$ & II 5 (2I.82\%) & & \\
\hline Middle school & 1623 (25.58\%) & 745 (24.50\%) & 783 (28.19\%) & 95 (I8.03\%) & & \\
\hline High school & 771 (12.15\%) & 385 (I2.66\%) & 347 (I2.49\%) & 39 (7.40\%) & & \\
\hline College and above & I 78 (2.79\%) & $73(2.40 \%)$ & 101 (4.44\%) & $4(0.76 \%)$ & & \\
\hline $\begin{array}{l}\text { Annual personal income } \\
\text { (RMB) }\end{array}$ & & & & & $70.331^{\mathrm{a}}$ & $<0.001$ \\
\hline$\leq 5 \mathrm{k}$ & 3702 (58.34\%) & 1822 (59.91\%) & 1498 (53.92\%) & 382 (72.49\%) & & \\
\hline$(5 k, 30 k)$ & 1435 (22.61\%) & 676 (22.23\%) & 679 (24.44\%) & 80 (I5.18\%) & & \\
\hline$\geq 30 \mathrm{k}$ & 1209 (19.05\%) & $543(17.86 \%)$ & $601(21.64 \%)$ & $65(12.33 \%)$ & & \\
\hline Smoking & & & & & $8.931^{\mathrm{a}}$ & 0.011 \\
\hline No & 4263 (67.18\%) & 2046 (67.28\%) & 1834 (66.02\%) & $383(72.68 \%)$ & & \\
\hline Yes & $2083(32.82 \%)$ & 995 (32.72\%) & 944 (33.98\%) & 144 (27.32\%) & & \\
\hline Drinking & & & & & $6.688^{\mathrm{a}}$ & 0.035 \\
\hline No & 3899 (61.44\%) & $1875(61.66 \%)$ & $1675(60.30 \%)$ & 349 (66.22\%) & & \\
\hline Yes & 2447 (38.56\%) & 1166 (38.34\%) & I I 03 (39.70\%) & 178 (33.78\%) & & \\
\hline Exercise & & & & & $15.825^{\mathrm{a}}$ & $<0.001$ \\
\hline No & $46 I(7.26 \%)$ & 221 (7.27\%) & $180(6.48 \%)$ & 60 (II.39\%) & & \\
\hline Yes & 5885 (92.74\%) & 2820 (92.73\%) & 2598 (93.52\%) & 467 (88.61\%) & & \\
\hline Subjective health & & & & & $83.818^{a}$ & $<0.001$ \\
\hline Poor & 813 (12.81\%) & 496 (16.31\%) & $258(9.29 \%)$ & 59 (II.20\%) & & \\
\hline Fair & 3049 (48.05\%) & |48| (48.70\%) & I 328 (47.80\%) & 240 (45.54\%) & & \\
\hline Good & $2484(39.14 \%)$ & 1064 (34.99\%) & 1192 (42.91\%) & $228(43.26 \%)$ & & \\
\hline No. of chronic disease & & & & & $36.375^{a}$ & $<0.001$ \\
\hline 0 & 3730 (58.78\%) & 1704 (56.03\%) & 1695 (6I.02\%) & 331 (62.81\%) & & \\
\hline I & 1587 (25.01\%) & 759 (24.96\%) & 704 (25.34\%) & 124 (23.53\%) & & \\
\hline$\geq 2$ & 1029 (16.21\%) & $578(19.01 \%)$ & 379 (I3.64\%) & 72 (13.66\%) & & \\
\hline Internet use & & & & & $49.384^{\mathrm{a}}$ & $<0.001$ \\
\hline No & 5166 (8I.4I\%) & 2497 (82.11\%) & 2187 (78.73\%) & 482 (91.46\%) & & \\
\hline Yes & $1180(18.59 \%)$ & $544(17.89 \%)$ & $591(21.27 \%)$ & $45(8.54 \%)$ & & \\
\hline Frequency & & & & & $50.075^{\mathrm{a}}$ & $<0.001$ \\
\hline Never & 5166 (8I.4I\%) & 2497 (82.11\%) & 2187 (78.73\%) & 482 (91.46\%) & & \\
\hline Not Regularly & $103(1.62 \%)$ & 45 (I.48\%) & $52(1.87 \%)$ & $6(1.14 \%)$ & & \\
\hline Regularly & 1077 (16.97\%) & 499 (16.41\%) & 539 (19.40\%) & 39 (7.40\%) & & \\
\hline
\end{tabular}


Table I (Continued).

\begin{tabular}{|c|c|c|c|c|c|c|}
\hline Variables & $\begin{array}{l}\text { Total } \\
(n=6346)\end{array}$ & $\begin{array}{l}\text { Short Sleep } \\
(n=304 I)\end{array}$ & $\begin{array}{l}\text { Normal Sleep } \\
(n=2778)\end{array}$ & $\begin{array}{l}\text { Long Sleep } \\
(n=527)\end{array}$ & $\chi^{2}$ & $p$ \\
\hline Variety & & & & & $53.342^{\mathrm{a}}$ & $<0.001$ \\
\hline 0 & $5166(81.41 \%)$ & 2497 (82.11\%) & $2187(78.73 \%)$ & 482 (91.46\%) & & \\
\hline I & 912 (14.37\%) & 428 (14.07\%) & 444 (I5.98\%) & 40 (7.59\%) & & \\
\hline$\geq 2$ & $268(4.22 \%)$ & $116(3.82 \%)$ & 147 (5.29\%) & 5 (0.95\%) & & \\
\hline Desktop use & & & & & $19.898^{\mathrm{a}}$ & $<0.001$ \\
\hline No & 6114 (96.34\%) & 2945 (96.84\%) & 2648 (95.32\%) & $52 \mathrm{I}(98.86 \%)$ & & \\
\hline Yes & $232(3.66 \%)$ & $96(3.16 \%)$ & 130 (4.68\%) & $6(1.14 \%)$ & & \\
\hline Cellphone use & & & & & $46.208^{a}$ & $<0.001$ \\
\hline No & 5209 (82.08\%) & 2517 (82.77\%) & 2209 (79.52\%) & 483 (91.65\%) & & \\
\hline Yes & II 37 (I7.92\%) & 524 (I7.23\%) & 569 (20.48\%) & 44 (8.35\%) & & \\
\hline Laptop use & & & & & $4.717^{\mathrm{a}}$ & 0.095 \\
\hline No & 6277 (98.91\%) & 3008 (98.91\%) & $2743(98.74 \%)$ & 526 (99.81\%) & & \\
\hline Yes & 69 (1.09\%) & 33 (1.09\%) & 35 (1.26\%) & I (0.19\%) & & \\
\hline Tablet use & & & & & $5.082^{\mathrm{a}}$ & 0.079 \\
\hline No & $6273(98.85 \%)$ & 3006 (98.85\%) & $274 \mid(98.67 \%)$ & 526 (99.81\%) & & \\
\hline Yes & 73 (1.15\%) & 35 (1.15\%) & 37 (1.33\%) & I (0.19\%) & & \\
\hline
\end{tabular}

Notes: ${ }^{a}$ Outcomes of Chi-squared test, ${ }^{b}$ Outcomes of Kruskal-Wallis $\mathrm{H}$-test. Age was represented by median and interquartile range.

females were more likely to have shorter sleep, while persons with better self-reported health were more likely to have longer sleep. Therefore, we adjusted these variables as confounding factors to analyze the relationships between internet use and sleep duration. However, after adjusting for all covariates, the association between internet use and short sleep was no longer significant $(0.929[0.803-1.075] p=$ 0.325 ), and no correlation was found for three dimensions. Only long sleep remained significant and with increased OR (0.612 [0.433-0.865] $p=0.005)$, and there were also increases in OR between other dimensions compared to the unadjusted model. Specifically, those who used the internet regularly $(0.583[0.404-0.840] p=0.004)$ and used more than two devices $(0.354$ [0.139-0.900] $p=0.029)$ were less likely to have a long sleep.

\section{Discussion}

Sleep is a universal healthy behavior. ${ }^{19,20}$ Understanding the underlying associated factors is of great health significance for global healthy aging. The study used the latest national data to investigate the association between internet use and sleep duration. As far as we know, this is the first study to explore the relationship between internet use and sleep duration by considering the variety, frequency and type of internet use.
After adjusting for all covariates, internet use was negatively correlated with long sleep duration in middleaged and elderly Chinese (0.612 [0.433-0.865] $p=0.005)$. However, we did not observe the same association with short sleep duration $(0.929[0.803-1.075] p=0.325)$, and none of the internet use variables predicted short sleep duration. This may be related to the purpose of using the internet. Studies showed that lack of sleep was significantly associated with internet use for leisure, but the relationship was not obvious for internet use for study. ${ }^{21}$

Our study found that it was difficult for persons who used the internet regularly $(0.583[0.404-0.840] p=0.004)$ and more than two devices $(0.354$ [0.139-0.900] $p=$ $0.029)$ to have a long sleep. There are several possible reasons for this phenomenon. First, sleep may be affected by content in electronic media. Irritating content contained in media may keep people mentally, emotionally, or physiologically aroused, resulting in difficulty falling asleep or poor quality of sleep. ${ }^{22}$ Second, studies have shown that melatonin can improve sleep. ${ }^{23}$ The biosynthesis of melatonin has a circadian rhythm, which is $5-10$ times more at night than during the day, and normally reaches a peak at 2-3 a.m. The light on the screen of electronics will affect the melatonin secretion. ${ }^{24,25}$ Third, internet use is a kind of unstructured leisure activity without a fixed starting and 
Table 2 Multinomial Regression Analysis for Internet Use and Sleep Duration

\begin{tabular}{|c|c|c|c|c|c|c|}
\hline & \multicolumn{2}{|c|}{ Unadjusted Model } & \multicolumn{2}{|c|}{ Model I } & \multicolumn{2}{|c|}{ Model 2} \\
\hline & Short vs Normal & Long vs Normal & Short vs Normal & Long vs Normal & Short vs Normal & Long vs Normal \\
\hline \multicolumn{7}{|c|}{ Internet use (Ref: No) } \\
\hline Yes & $0.806[0.708-0.918]^{* *}$ & $0.345[0.251-0.475]^{* * * *}$ & $0.88 \mathrm{I}[0.770-1.008]$ & $0.432[0.312-0.599]^{* * *}$ & $0.929[0.803-1.075]$ & $0.612[0.433-0.865]^{* *}$ \\
\hline \multicolumn{7}{|c|}{ Frequency (Ref: Never) } \\
\hline Not Regularly & $0.758[0.506-1.134]$ & $0.524[0.224-1.226]$ & $0.838[0.559-1.258]$ & $0.684[0.291-1.610]$ & $0.888[0.589-1.338]$ & $0.896[0.378-2.124]$ \\
\hline Regularly & $0.811[0.709-0.928]^{* *}$ & $0.328[0.234-0.461]^{* * * *}$ & $0.885[0.770-1.017]$ & $0.409[0.290-0.579]^{* *}$ & $0.933[0.802-1.086]$ & $0.583[0.404-0.840]^{* *}$ \\
\hline \multicolumn{7}{|c|}{ Variety (Ref: None) } \\
\hline 1 & $0.844[0.731-0.976]^{*}$ & $0.409[0.291-0.573]^{* * *}$ & $0.920[0.793-1.068]$ & $0.510[0.36 \mathrm{I}-0.720]^{* * *}$ & $0.955[0.817-1.116]$ & $0.666[0.465-0.954]^{*}$ \\
\hline$\geq 2$ & $0.691[0.538-0.888]^{*}$ & $0.154[0.063-0.378]^{* * * *}$ & $0.763[0.592-0.982]^{*}$ & $0.195[0.079-0.479]^{* * * *}$ & $0.827[0.626-1.092]$ & $0.354[0.139-0.900]^{*}$ \\
\hline \multicolumn{7}{|c|}{ Desktop use (Ref: No) } \\
\hline Yes & $0.664[0.507-0.869]^{* *}$ & $0.235[0.103-0.535]^{* *}$ & $0.723[0.552-0.948]^{*}$ & $0.288[0.126-0.659]^{* *}$ & 0.784 [0.587-1.048] & $0.550[0.234-1.293]$ \\
\hline \multicolumn{7}{|c|}{ Cellphone use (Ref: No) } \\
\hline Yes & $0.808[0.708-0.922]^{* *}$ & $0.354[0.256-0.488]^{* * *}$ & $0.885[0.772-1.015]$ & $0.446[0.321-0.620]^{* * *}$ & $0.932[0.804-1.081]$ & $0.627[0.443-0.889]^{* *}$ \\
\hline \multicolumn{7}{|c|}{ Laptop use (Ref: No) } \\
\hline Yes & $0.860[0.533-1.387]$ & $0.149[0.020-1.090]$ & $0.954[0.590-1.542]$ & $0.193[0.026-1.416]$ & $1.089[0.662-1.792]$ & $0.375[0.050-2.807]$ \\
\hline \multicolumn{7}{|c|}{ Tablet use (Ref: No) } \\
\hline Yes & $0.863[0.542-1.373]$ & $0.141[0.019-1.029]$ & $0.894[0.561-1.426]$ & $0.159[0.022-1.163]$ & $0.968[0.600-1.564]$ & $0.292[0.039-2.165]$ \\
\hline
\end{tabular}

Notes: The results were quantified by OR, with a confidence intervals in square brackets. $* p<0.05, * * p<0.01$, $* * * p<0.00 \mathrm{I}$. Model I adjusted for age and gender. Model 2 adjusted for age, gender, marital status, education, annual personal income, health behavior-related factors; and health status.

stopping point, which is easy to expand and take up more time, thus replacing sleep. ${ }^{26}$

Among the four internet devices, we found that cellphone use was significantly correlated with sleep duration $(0.627[0.443-0.889] p=0.009)$. Like many other research results, ${ }^{27}$ cellphone had a negative effect on sleep - using cellphone could reduce sleep duration, possibly because the radiation produced by cellphones could delay the onset of melatonin. ${ }^{28,29}$ On the other hand, many people still have the urge to use mobile phones during the sleep period, which increases the risk of sleep deprivation. A study from Copenhagen continuously monitored 815 young adults over a four-week period. The results showed that $75 \%$ of the respondents used a mobile phone within one hour before reported bedtime, and $12-15 \%$ of the respondents still used a mobile phone during their reported sleep period. ${ }^{30}$

As far as we know, this study is the latest to use nationwide data from China to examine the relationship of different variety, frequency, and type of internet use with sleep duration. With the large sample size and good representativeness, CHARLS data has been widely used and acknowledged in academic circles. Secondly, trained and qualified researchers gathered all data from interactive face-to-face interviews to ensure the accuracy of the information. Finally, when we obtained the results of sleep duration, we asked participants "how many hours of actual sleep did you get at night", not the interval between bedtime and rise time, which reduced the effect of sleep latency (the difference in time between going to bed and actually falling asleep).

There are also some limitations in our study. First, our study design is a cross-sectional survey. Although we assumed that internet use will influence sleep duration, it is difficult to validate without conducting a longitudinal study. Second, since CHARLS is a public database, we have no way to verify the missing data and the reasons. Therefore, we finally decided to delete the missing data, which may have lose some of representativeness. Due to the limited data available, we are unable to include the specific length and purpose of internet use. Future research may analyze the impact of the internet through more in- 
depth measurements. Third, self-reported sleep duration may be less accurate compared to the artificial setting of a sleep laboratory.

\section{Conclusion}

In conclusion, after controlling for potential confounders, internet use was significantly negatively associated with long sleep duration, but not with short sleep duration. Persons who used the internet regularly and used one device and more than two devices were more difficult to have a long sleep. Of the four specific internet devices, only cellphone use was significantly negatively associated with long sleep duration.

Sleep problems are multi-causal, including a range of physical, mental and social factors. Future research can combine the internet with other predictors of sleep, promote interdisciplinary development and provide reference for sleep hygiene.

\section{Ethical Approval}

The data accessed from the China Health and Retirement Longitudinal Study is freely available (available from: http://charls.pku.edu.cn/index/zh-cn.html). This research does not require review and approval by an institutional review board or ethics committee, and we confirmed that the data accessed by the manuscript complies with relevant data protection and privacy regulations.

\section{Funding}

This research received no specific grant from any funding agency in the public, commercial, or not-for-profit sectors.

\section{Disclosure}

The authors report no conflicts of interest in this work.

\section{References}

1. Anderberg P, Skär L, Abrahamsson L, Berglund JS. Older people's use and nonuse of the internet in Sweden. Int J Environ Res Public Health. 2020;17(23):9050. doi:10.3390/ijerph17239050

2. China Internet Network Information Center (CNNIC). The 45th China statistical report on internet development. Available from: http://www. cac.gov.cn/2020-04/27/c_1589535470378587.htm. Accessed January 7, 2021.

3. Knutson KL. Sleep duration and cardiometabolic risk: a review of the epidemiologic evidence. Best Pract Res Clin Endocrinol Metab. 2010;24(5):731-743. doi:10.1016/j.beem.2010.07.001

4. Reutrakul S, Van Cauter E. Sleep influences on obesity, insulin resistance, and risk of type 2 diabetes. Metabolism. 2018;84:56-66. doi:10.1016/j.metabol.2018.02.010

5. Knutson KL. Sociodemographic and cultural determinants of sleep deficiency: implications for cardiometabolic disease risk. Soc Sci Med. 2013;79:7-15. doi:10.1016/j.socscimed.2012.05.002
6. Huajun X, Yunyan X, Xinyi L, et al. Association between obstructive sleep apnea and lipid metabolism during REM and NREM sleep. J Clin Sleep Med. 2020;16(4):475-482. doi:10.5664/ jcsm. 8242

7. Takahashi A, Anzai Y, Kuroda M, et al. Effects of sleep quality on non-alcoholic fatty liver disease: a cross-sectional survey. BMJ Open. 2020;10(10):e039947. doi:10.1136/bmjopen-2020-039947

8. Geiger SD, Sabanayagam C, Shankar A. The relationship between insufficient sleep and self-rated health in a nationally representative sample. J Environ Public Health. 2012;2012:518263. doi:10.1155/ $2012 / 518263$

9. Zitting K, Lammers-van Der Holst HM, Yuan RK, et al. Google trends reveal increases in internet searches for insomnia during the COVID-19 global pandemic. J Clin Sleep Med. 2021;17(2):177-184. doi: $10.5664 /$ jcsm. 8810

10. Hysing M, Pallesen S, Stormark KM, et al. Sleep and use of electronic devices in adolescence: results from a large population-based study. BMJ Open. 2015;5(1):e6748. doi:10.1136/bmjopen-2014006748

11. Exelmans L, Van den Bulck J. Bedtime mobile phone use and sleep in adults. Soc Sci Med. 2016;148:93-101. doi:10.1016/j. socscimed.2015.11.037

12. Altena E, Baglioni C, Espie CA, et al. Dealing with sleep problems during home confinement due to the COVID-19 outbreak: practical recommendations from a task force of the European CBT-I academy. J Sleep Res. 2020;29(4):e13052. doi:10.1111/jsr.13052

13. Sherman LD, Goidel K, Bergeron CD, Smith ML. Web-based health information seeking among African American and hispanic men living with chronic conditions: Cross-sectional Survey Study. J Med Internet Res. 2021;23(7):e26180. doi:10.2196/26180

14. Madrigal L, Escoffery C. Electronic health behaviors among US adults with chronic disease: cross-sectional survey. $J$ Med Internet Res. 2019;21(3):e11240. doi:10.2196/11240

15. Cui F, He X, Zhai Y, et al. Application of telemedicine services based on a regional telemedicine platform in China from 2014 to 2020: longitudinal trend analysis. J Med Internet Res. 2021;23(7):e28009. doi:10.2196/28009

16. Zhao Y, Hu Y, Smith JP, Strauss J, Yang G. Cohort profile: the China health and retirement longitudinal study (CHARLS). Int J Epidemiol. 2014;43(1):61-68. doi:10.1093/ije/dys203

17. Hirshkowitz M, Whiton K, Albert SM, et al. National Sleep Foundation's sleep time duration recommendations: methodology and results summary. Sleep Health. 2015;1(1):40-43. doi:10.1016/j. sleh.2014.12.010

18. Ouyang P, Sun W. Depression and sleep duration: findings from middle-aged and elderly people in China. Public Health. 2019;166:148-154. doi:10.1016/j.puhe.2018.10.007

19. Sithey G, Wen LM, Kelly P, Li M. Association between sleep duration and self-reported health status: findings from the Bhutan's Gross National Happiness Study. J Clin Sleep Med. 2017;13(1):33-38. doi: $10.5664 / \mathrm{jcsm} .6382$

20. Kim J, Kim KR, Cho KH, et al. The association Between sleep duration and self-rated health in the Korean General population. J Clin Sleep Med. 2013;9(10):1057-1064. doi:10.5664/jcsm.3082

21. Kim SY, Kim M, Park B, Kim J, Choi HG, Lepp A. Lack of sleep is associated with internet use for leisure. PLoS One. 2018;13(1): e0191713. doi:10.1371/journal.pone.0191713

22. Van den Bulck J. The effects of media on sleep. Adolesc Med State Art Rev. 2010;21(3):418-429.

23. Fatemeh G, Sajjad M, Niloufar R, et al. Effect of melatonin supplementation on sleep quality: a systematic review and meta-analysis of randomized controlled trials. $J$ Neurol. In press 2021. doi:10.1007/ s00415-020-10381-w

24. Lewy AJ, Wehr TA, Goodwin FK, Newsome DA, Markey SP. Light suppresses melatonin secretion in humans. Science. 1980;210 (4475):1267-1269. doi:10.1126/science.7434030 
25. Chellappa SL, Steiner R, Oelhafen P, et al. Acute exposure to evening blue-enriched light impacts on human sleep. J Sleep Res. 2013;22 (5):573-580. doi:10.1111/jsr. 12050

26. Kubey RW. Television use in everyday life: coping with unstructured time. $J$ Commun. 1986;36(3):108-123. doi:10.1111/j.14602466.1986.tb01441.x

27. Alshobaili FA, AlYousefi NA. The effect of smartphone usage at bedtime on sleep quality among Saudi non- medical staff at King Saud University Medical City. J Family Med Prim Care. 2019;8 (6):1953-1957. doi:10.4103/jfmpc.jfmpc_269_19
28. Wood AW, Loughran SP, Stough C. Does evening exposure to mobile phone radiation affect subsequent melatonin production? Int J Radiat Biol. 2006;82(2):69-76. doi:10.1080/09553000600599775

29. Lowden A, Akerstedt T, Ingre $M$, et al. Sleep after mobile phone exposure in subjects with mobile phone-related symptoms. Bioelectromagnetics. 2011;32(1):4-14. doi:10.1002/bem.20609

30. Rod NH, Dissing AS, Clark A, Gerds TA, Lund R, van Wouwe JP. Overnight smartphone use: a new public health challenge? A novel study design based on high-resolution smartphone data. PLoS One. 2018;13(10):e204811. doi:10.1371/journal.pone.0204811

\section{Publish your work in this journal}

The International Journal of General Medicine is an international, peer-reviewed open-access journal that focuses on general and internal medicine, pathogenesis, epidemiology, diagnosis, monitoring and treatment protocols. The journal is characterized by the rapid reporting of reviews, original research and clinical studies across all disease areas. The manuscript management system is completely online and includes a very quick and fair peer-review system, which is all easy to use. Visit http://www.dovepress.com/ testimonials.php to read real quotes from published authors. 